\title{
Management of postoperative atrial fibrillation
}

\author{
Takeshi Omae $\cdot$ Yuichi Kanmura
}

Received: 9 November 2011/Accepted: 9 January 2012/Published online: 25 January 2012

(C) The Author(s) 2012. This article is published with open access at Springerlink.com

\begin{abstract}
The impact of postoperative atrial fibrillation (PAF) on patient outcomes has prompted intense investigation into the optimal methods for prevention and treatment of this complication. In the prevention of PAF, $\beta$-blockers and amiodarone are particularly effective and are recommended by guidelines. However, their use requires caution due to the possibility of drug-related adverse effects. Aside from these risks, perioperative prophylactic treatment with statins seems to be effective for preventing PAF and is associated with a low incidence of adverse effects. PAF can be treated by rhythm control, heart-rate control, and antithrombotic therapy. For the purpose of heart rate control, $\beta$ blockers, calcium-channel antagonists, and amiodarone are used. In patients with unstable hemodynamics, cardioversion may be performed for rhythm control. Antithrombotic therapy is used in addition to heart-rate maintenance therapy in cases of PAF $>48$-h duration or in cases with a history of cerebrovascular thromboembolism. Anticoagulation is the first choice for antithrombotic therapy, and anticoagulation management should focus on maintaining international normalized ratio (INRs) in the 2.0-3.0 range in patients $<75$ years of age, whereas prothrombin-time INR should be controlled to the 1.6-2.6 range in patients $\geq 75$ years of age. In the future, dabigatran could be used for perioperative management of PAF, because it does not require regular monitoring and has a quick onset of action with short serum
\end{abstract}

T. Omae $(\bowtie)$

Department of Anesthesiology, Fujimoto Hayasuzu Hospital,

17-1 Hayasuzu, Miyakonojo, Miyazaki 885-0055, Japan

e-mail: omae@za2.so-net.ne.jp

Y. Kanmura

Departments of Anesthesiology and Critical Care Medicine,

Kagoshima University, Graduate School of Medical

and Dental Sciences, Kagoshima, Kagoshima, Japan half-life. Preventing PAF is an important goal and requires specific perioperative management as well as other approaches. PAF is also associated with lifestyle-related diseases, which emphasizes the ongoing need for appropriate lifestyle management in individual patients.

Keywords Atrial fibrillation - Cardiovascular surgery · Statins $\cdot$ Rate control $\cdot$ Anticoagulant therapy

\section{Introduction}

Postoperative atrial fibrillation (PAF) is the most frequent complication that occurs after cardiovascular surgery (Table 1) [1]. The incidence of cardiovascular events, such as cerebral infarction and heart failure, increases by twofold in the presence of chronic atrial fibrillation (AF) [2]. Conventional viewpoints suggest that PAF is less likely to affect the survival of patients when compared with chronic $\mathrm{AF}$, although it does slightly prolong the duration of hospital stay. However, reports suggest that PAF is associated with a significant incidence of various complications, including cardiovascular events, renal failure, infection, and cerebral infarction [3]. PAF is affected by diverse factors, and a wide variety of strategies has been shown to be useful in preventing or treating PAF. This article outlines the etiology, characteristics, and PAF prevention and treatment, citing the latest findings from published reports.

\section{PAF characteristics}

$\mathrm{AF}$ is the most frequent complication arising after coronary artery bypass (CAB) surgery, occurring in $30 \%$ of cases. 
Table 1 Postoperative complications after coronary artery bypass grafting

\begin{tabular}{ll}
\hline Complication & Percent of patients \\
\hline Rethoracotomy & 2 \\
Renal failure & 5 \\
Cerebral infarction & 2.5 \\
Respiratory failure & 6 \\
Gastrointestinal failure & 2 \\
Atrial fibrillation & 30 \\
\hline
\end{tabular}

The incidence of this complication is even higher after valve-replacement surgery (30-40\%) and after compound operative procedures (40-60\%) [4]. The onset of AF has also been reported after nonheart surgery, such as pulmonary lobectomy (10-20\%) and total pneumonectomy (40\%) [5]. PAF most frequently develops on the second postoperative day. Although often transient, it recurs in $40 \%$ of cases [3]. Historically, in contrast to chronic AF, PAF was thought to be relatively unlikely to affect patient survival. However, more recent studies suggest that PAF increases the duration of intensive care unit (ICU) stay (2.0 days in the no-PAF group vs. 3.6 days in the PAF group, $p<0.001$ ), duration of hospital stay (7 days in the no-PAF group vs. 10 days in the PAF group, $p<0.001$ ), and is associated with a twofold elevation in the incidence of cerebral infarction (2.4\% in the no-PAF group vs. $5.3 \%$ in the PAF group, $p<0.001)$ and a increased risk of 30-day mortality $(3.0 \%$ in the no-PAF group vs. $6.0 \%$ in the PAF group, $p<0.001)$. Furthermore, PAF was an independent predictor of long-term mortality [adjusted odds ratio (OR) 1.5, $p<0.001]$ in a retrospective cohort; OR 3.4, $p<0.0018$ in a case-matched population. [4]. Thus, PAF appears to have a significant effect on the acute postoperative condition of patients as well as on their longterm prognosis.

Preoperative factors associated with an increased risk of developing PAF are summarized in Table 2. The incidence of PAF is particularly high among elderly patients $[4,6,7]$, especially in those $>70$ years of age [8]. Conventional risk factors for PAF include left atrial dilatation and left ventricular hypertrophy [7, 8]; other risk factors include diabetes mellitus [7, 8], obesity, and metabolic syndrome [9]. A recent study reported that obesity is an independent risk factor for PAF in those undergoing cardiovascular surgery, especially in patients $>50$ years of age $[10,11]$. Intraoperative risk factors for PAF are summarized in Table 3 and include atrial injury, atrial ischemia, insertion of a vascular catheter, and sudden changes in circulating blood volume [7-9]. Furthermore, cardiovascular surgery using cardiopulmonary bypass is likely to induce an inflammatory reaction, triggering the onset of PAF [12]. Postoperative
Table 2 Preoperative risk factors for postoperative atrial fibrillation Risk factors

\begin{tabular}{ll}
\hline Old age & Diabetes \\
Enlargement of the left atrium & Obesity \\
Left ventricular hypertrophy & Metabolic syndrome \\
Hypertension & \\
\hline
\end{tabular}

Table 3 Intraoperative risk factors for postoperative atrial fibrillation Risk factors

Damage to the atrium

Insertion of a ventilator tube

Myocardial ischemia

Venous cannulation

Acute volume change

Table 4 Postoperative risk factors for postoperative atrial fibrillation Risk factors

\begin{tabular}{ll}
\hline Volume overload & Atrial extrasystole \\
Increased afterload & Imbalance of the autonomic nervous system \\
Hypotension & Electrolyte imbalance \\
Inflammation & \\
\hline
\end{tabular}

risk factors for PAF are summarized in Table 4 and include volume overload, electrolyte abnormalities, atrial extrasystole, and sympathetic hyperactivity [10]. In addition, studies suggest that inflammatory reactions are a risk factor for PAF [13, 14]. Delineation of these novel risk factors for PAF has led to the development of new strategies for treating and preventing PAF.

\section{Preventing PAF}

Conventionally, nondihydropyridine calcium-channel antagonists and digitalis have been used for treating PAF $[15,16]$. Although nondihydropyridine calcium-channel antagonists are effective against supraventricular tachycardia [17], they are also frequently associated with adverse reactions (e.g., atrioventricular block, heart failure, etc.) [18] and are therefore not the ideal agents to use for prophylactic purposes. Further, one meta-analysis reported that digitalis was ineffective when used for PAF prevention. This is probably because digitalis acts on vagal tone and therefore reduces the ventricular rate during atrial arrhythmias. Therefore, this benefit of digitalis may be attenuated during the perioperative period, in which there is increased sympathetic tone [19]. Methods reported to be useful in PAF prevention are summarized in Table 5. 
Table 5 Prevention of postoperative atrial fibrillation

\begin{tabular}{ll}
\hline Preventive measures & \\
\hline$\beta$-blockers & Steroids \\
Amiodarone & Statins \\
OPCAB & Pacing \\
\hline
\end{tabular}

$O P C A B$ off-pump coronary artery bypass grafting

\section{$\beta$-blockers}

$\beta$-blockers have direct antiarrhythmic activity on stimulus conduction cells and myocardial cells and are classified as class II antiarrhythmic agents according to the VaughanWilliams classification. $\beta$-blockers are effective against tachycardic arrhythmia [20], supraventricular arrhythmia [21], and lidocaine-resistant ventricular fibrillation [22]. Perioperative prophylactic use of $\beta$-blockers could decrease cardiovascular events [23-31]. Coleman et al. [32] reported that postoperative $\beta$-blockers reduced hospital length of stay [mean \pm standard deviation (SD) $10.22 \pm 11.38$ in the $\beta$-blocker group vs. $12.40 \pm 15.67$ in the placebo group; $p=0.001]$ and PAF $(23.5 \%$ in the $\beta$ blocker group vs. $28.4 \%$ in the placebo group; $p=0.02$ ). Crystal et al. [33] reported that $\beta$-blockers had the greatest magnitude of effect for PAF prevention in a meta-analysis [OR 0.35; 95\% confidence interval (CI) 0.26-0.49]. Lindenauer et al. [34] reported that prophylactic $\beta$-blockers were associated with a reduced risk of in-hospital death in patients with a Revised Cardiac Risk Index (RCRI, which is based on the presence of history of ischemic heart disease, cerebrovascular disease, renal insufficiency, diabetes mellitus, or a patient undergoing high-risk surgery) of score $\geq 3$ but not in patients with a RCRI score of 2,1 , or 0 . Thus, that study demonstrated an association between improved outcomes and the use of $\beta$-blockers in clinically high-risk patients, whereas lower-risk patients had worse outcomes. The PeriOperative Ischemia Study Evaluation (POISE) trial [35], which was a large, randomized, controlled trial of fixed, high-dose, extended-release metoprolol starting on the day of surgery in more than 8,000 patients undergoing noncardiac surgery, demonstrated that perioperative $\beta$ blocker treatment reduced the incidence of cardiovascular events $[5.8 \%$ patients in the metoprolol group vs. $6.9 \%$ patients in the placebo group; hazard ratio (HR) $0.84 ; 95 \%$ CI $0.70-0.99 ; p=0.04]$ but increased the total death rate (3.1 vs. $2.3 \%$; HR $1.33,95 \%$ CI $1.03-1.74 ; p=0.03$ ) or the incidence of stroke (1.0 vs. $0.5 \%$; HR $2.17 ; 95 \% \mathrm{CI}$ $1.26-3.74 ; p=0.005$ ), possibly due to $\beta$-blocker-induced hypotension (15 vs. 9.7\%; HR 1.55; 95\% CI 1.38-1.74) and bradycardia (6.6 vs. 2.4\%; HR 2.74; 95\% CI 2.19-3.43). Further, a meta-analysis of data from 33 randomized controlled trials (RCTs) reported that $\beta$-blocker
Table 6 Classification of recommendations

ACC/AHA/ESC guideline recommendations

Class

Class I

Conditions for which there is evidence and/or general agreement that a given procedure/ therapy is beneficial, useful, and effective

Class II

Conditions for which there is conflicting evidence and/or a divergence of opinion about the usefulness/efficacy of performing the procedure/ therapy

Class IIa Weight of evidence/opinion is in favor of usefulness/efficacy

Class IIb Usefulness/efficacy is less well established by evidence/opinion

Class III Conditions for which there is evidence and/or general agreement that a procedure/therapy is not useful or effective and in some cases may be harmful

Level of evidence

$\begin{array}{ll}\begin{array}{l}\text { Level of } \\ \text { evidence A }\end{array} & \begin{array}{c}\text { Data derived from multiple randomized clinical } \\ \text { trials or meta-analyses }\end{array} \\ \begin{array}{l}\text { Level of } \\ \text { evidence B }\end{array} & \begin{array}{c}\text { Data derived from a single randomized trial, or } \\ \text { nonrandomized studies }\end{array} \\ \begin{array}{l}\text { Level of } \\ \text { evidence C }\end{array} & \begin{array}{c}\text { Only consensus opinion of experts, case studies, or } \\ \text { standard of care }\end{array}\end{array}$

Classification of recommendations and level of evidence are expressed in the ACC/AHA/ESC format. Recommendations are evidence based and derived primarily from published data

Weight of evidence is ranked from highest (A) to lowest (C)

ACC American College of Cardiology, AHA American Heart Association, ESC European Society of Cardiology

treatment reduced nonfatal myocardial infarction (MI) (OR 0.65 ; 95\% CI $0.54-0.79$ ) and myocardial ischemia (OR 0.36 ; $95 \%$ CI $0.26-0.50$ ) but increased nonfatal strokes (OR 2.01; 95\% CI 1.27-3.68) and the incidence of bradycardia (OR 3.13; 95\% CI 2.51-3.92) and hypotension (OR 1.69; 95\% CI 1.39-2.65) that required treatment [36]. These data suggest that prophylactic $\beta$-blockers should be used with caution. Guidelines for using $\beta$-blockers were updated after results from the POISE trial became available. At present, unless contraindicated, treatment with $\beta$ blockers is recommended to prevent PAF [Class I, level of evidence (LOE) A; Table 6] in the American College of Cardiology (ACC)/American Heart Association (AHA)/ European Society of Cardiology (ESC) Guidelines for the Management of Patients with Atrial Fibrillation [37]. Further, preoperative or early postoperative administration of $\beta$-blockers in patients without contraindications should be used as standard therapy to reduce the incidence and/or clinical sequelae of $\mathrm{AF}$ and is recommended in the ACC/ AHA Guideline Update for Coronary Artery Bypass Graft Surgery (Class I, LOE B; Table 6) [38]. The POISE trial did not study continuation of $\beta$-blockers in patients 
undergoing surgery who are receiving $\beta$-blockers for the ACC/AHA Class I guideline indications. The guidelines on perioperative cardiovascular evaluation and care for noncardiac surgery also state that $\beta$-blockers should be continued in patients undergoing surgery who are receiving $\beta$-blockers for treatment of conditions with ACC/AHA Class I guideline indications for the drugs (Class I, LOE C; Table 6) [39].

\section{Amiodarone}

Amiodarone is a multichannel blocker possessing $\alpha, \beta$, potassium $\left(\mathrm{K}^{+}\right)$channel, sodium $\left(\mathrm{Na}^{+}\right)$and calcium $\left(\mathrm{Ca}^{2+}\right)$ blocking actions. It is a Class III antiarrhythmic agent according to the Vaughan-Williams classification. Amiodarone regimens are used to prevent or treat PAF. In one report, a 1-week preoperative oral regimen decreased the incidence of PAF (25\% patients in the amiodarone group vs. $53 \%$ patients in the placebo group, $p=0.03$ ) [40], postoperative intravenous treatment decreased the incidence of PAF when compared with placebo (35\% patients in the amiodarone group vs. $47 \%$ patients in the placebo group, $p=0.01$ ) [41], and treatment throughout the perioperative period decreased the incidence of PAF when compared with placebo (16\% patients in the amiodarone group vs. $25 \%$ patients in the placebo group, $p=0.001$ ) [42]. Amiodarone is also recommended as an appropriate means of preventing AF in high-risk patients (LOE A, Class IIa; Table 6) [37]. However, a meta-analysis of randomized placebo-controlled trials showed that perioperative amiodarone treatment was associated with an increase in the incidence of adverse reactions (1.7-fold in bradycardia and 1.6-fold in hypotension) [43]. Risk factors for amiodarone-related adverse reaction included intravenous administration, and administration of $>1 \mathrm{~g}$ per day [43]. In view of these findings, it is advisable to avoid prophylactic amiodarone treatment in patients at low risk for developing PAF. In those who do require prophylactic treatment, clinicians should be aware of the potential for adverse reactions (bradycardia, hypotension, etc.) during the use of this drug. $\beta$-blockers and amiodarone are particularly effective for perioperative prophylactic treatment and are recommended for this purpose in the Medical Society guidelines [37-39]. Otherwise, clinicians should be cognizant that there is a risk of drugrelated adverse reactions, particularly bradycardia and hypotension, when using these drugs.

\section{Statins}

Autopsy studies have demonstrated the role of plaque rupture and erosion in the pathophysiology of acute coronary syndrome. Statins have pleiotropic action, including the modification of atherosclerotic plaques and the improvement of endothelial function. Inflammation plays a role in the pathogenesis of atherosclerosis, and the antiinflammatory properties of stains likely account for their ability to reduce the incidence of PAF and perioperative cardiovascular events $[44,45]$. Mariscalco et al. reported that PAF occurred in $29.5 \%$ of patients receiving preoperative statin therapy when compared with $40.9 \%$ of patients who were not receiving such therapy $(p=0.021)$. Preoperative statins were associated with a $42 \%$ reduction in the risk of $\mathrm{AF}$ development after $\mathrm{CAB}$ surgery (OR 0.58; $95 \%$ CI $0.37-0.91, p=0.017$, stratified by propensity score) [46]. A meta-analysis of randomized trials of the use of preoperative statins reported that statins significantly reduced postoperative MI [risk ratio (RR) 0.57; CI $0.46-0.70 ; p<0.0001]$, and PAF (RR $0.54 ; 95 \% \mathrm{CI}$ $0.43-0.68 ; p<0.0001$ ) [47]. Guidelines do not specifically recommend the use of statins before cardiovascular surgery for the express purpose of preventing periprocedural complications, such as PAF. However, at present, perioperative prophylactic treatment with statins that have few side effects seems to be appropriate for PAF prevention of PAF.

\section{Anti-inflammatory drugs}

Cardiovascular surgery with cardiopulmonary bypass is associated with a systemic inflammatory response, which may be in part responsible for PAF. Patients with PAF tend to have significantly higher C-reactive protein (CRP), higher white blood cell (WBC) counts, and higher levels of inflammatory cytokines when compared with patients who do not develop PAF [48, 49]. This finding suggests that inflammatory reactions may be important in the pathogenesis of PAF [48, 49]. In nonsurgical patients, corticosteroid treatment may reduce the incidence of recurrent AF. Halonen et al. [50] reported that the administration of $100 \mathrm{mg}$ of hydrocortisone reduced PAF when compared with placebo in a randomized control trial $30 \%$ in the 100 -mg hydrocortisone group vs. $48 \%$ in the placebo group; adjusted HR 0.54 ; 95\% CI $0.35-0.83, p=0.004)$. Corticosteroids have anti-inflammatory properties. Several studies have indicated that the postoperative concentration of CRP was significantly lower in patients who received hydrocortisone than in patients who did not. Corticosteroids also reduce postoperative nausea, vomiting, and anorexia. Thus, corticosteroid therapy may improve absorption of orally administered medications, such as $\beta$-blockers, and thereby reduce the incidence of PAF. Cheruku et al. administrated $30 \mathrm{mg}$ ketorolac intravenously every $6 \mathrm{~h}$ until patients were able to take medications orally; then, patients were switched to ibuprofen $600 \mathrm{mg}$ orally three times a day for a total of 7 days or until discharge, whichever was longer [nonsteroidal anti-inflammatory drug 
(NSAID) group]. The authors reported that NSAIDs reduced the incidence of PAF $(9.8 \%$ vs. $28.6 \%$ in the placebo group) [51]. However, NSAIDs are associated with nephrotoxicity, particularly when used in the postoperative period, and in elderly patients.

\section{Magnesium}

Some studies have reported that serum magnesium levels are low in patients who develop PAF [52] and that tachycardia arrhythmia is closely related to the magnesium level [53]. A meta-analysis demonstrated that magnesium administration decreased the proportion of patients developing postoperative $\mathrm{AF}$ from $28 \%$ in the control group to $18 \%$ in the treatment group (OR $0.54 ; 95 \%$ CI $0.38-0.75$ ) [54]. In another meta-analysis, magnesium prevented PAF (OR 0.57; 95\% CI 0.42-0.77), but there was significant heterogeneity $(p<0.001)$ [29]. These meta-analyses included a small number of patients, and the design varied among the different studies, which limits the interpretation of the results. Although there are some data to suggest that perioperative administration of magnesium can prevent PAF in a manner similar to perioperative treatment with antiarrhythmic drugs, this notion remains controversial.

\section{Off-pump coronary artery bypass grafting (OPCAB)}

$\mathrm{CAB}$ surgery can be divided into procedures that use extracorporeal circulation and those that do not (OPCAB). OPCAB requires less manipulation of the aorta and avoids the use of cardiopulmonary bypass and may therefore cause less postoperative complications [55]. The incidence of PAF is lower following OPCAB when compared with conventional $\mathrm{CAB}$ surgery using cardiopulmonary bypass (OR 0.78; 95\% CI $0.74-0.82 ; p<0.0001$ in an observational study; OR $0.59 ; 95 \%$ CI $0.46-0.77 ; p<0.0001$ in a randomized controlled study) [55]. However, revascularization procedures did not affect postoperative mortality or stroke rates in a recent cohort study [56] and did not affect the incidence of PAF in a recent randomized trial [57]. In high-risk patients, Moller et al. [58] reported that the incidence of cardiovascular events, including PAF, was similar when comparing on-pump and off-pump revascularization. Thus, it remains controversial whether or not $\mathrm{OPCAB}$ reduces the incidence of PAF.

\section{Atrial pacing}

Prophylactic atrial pacing to prevent PAF after cardiovascular surgery is based on the fact that pacing is thought to favorably influence intra-atrial conduction and atrial refractoriness. There are several mechanisms by which atrial pacing might prevent AF: reduction of the bradycardia-induced dispersion of atrial repolarization, avoidance of the trigger for AF by overdrive suppression, and changing atrial activation pattern by dual-site atrial pacing [10]. Meta-analyses have demonstrated that singlesite atrial pacing and biatrial pacing can reduce the incidence of PAF [29, 33, 59]. Fan et al. [60] compared these two methods of atrial pacing and reported that biatrial pacing was superior in terms of maintaining interatrial conduction and is thus more useful in terms of preventing PAF than single-site atrial pacing. However, the number of enrolled patients was small, and the protocols varied widely among studies. Indeed, a major adverse effect of prophylactic atrial pacing is its potential proarrhythmic effect, which might be precipitated by inappropriate sensing or loss of pacing through temporary wires. Further, biatrial pacing requires complex manipulations, which has limited its use as a means of preventing AF to only a small number of facilities. Further study is required to evaluate the utility of atrial pacing in PAF prevention.

\section{Treating PAF}

PAF is typically transient and often requires no treatment. However, therapeutic intervention is needed in patients with compromised heart function, duration of $\mathrm{AF}>48 \mathrm{~h}$, and high-risk patients with cerebral thromboembolism [37, 38, 61]. PAF can be treated by rhythm control, heart-rate control, and antithrombotic therapy, similar to the methods used for treating chronic AF. The Atrial Fibrillation FollowUp Investigation of Rhythm Management (AFFIRM) study [62], which compared multiple methods of treatment for chronic AF, and the Rate Control versus Electrical (RACE) cardioversion for persistent atrial fibrillation trial [63] found that rate control was not inferior to rhythm control for preventing death and morbidity because antiarrhythmic agents used for rhythm control are associated with various adverse effects, including cardiac depression and a paradoxical increase in dangerous arrhythmias. Rate control with pharmacologic agents (either a $\beta$-blocker or a nondihydropyridine calcium-channel antagonist, in most cases) is recommended for patients with persistent or permanent AF. In the acute setting, intravenous administration of $\beta$ blockers (esmolol, metoprolol, or propranolol) or nondihydropyridine calcium-channel antagonists (verapamil, diltiazem) and amiodarone is recommended in order to slow the ventricular response to $\mathrm{AF}$, exercising caution in patients with hypotension or heart failure [64]. $\beta$-blockers are more effective than calcium-channel antagonists for controlling the ventricular response during AF [65]. Further, $\beta$-blockers accelerate the conversion of postoperative supraventricular arrhythmias to sinus rhythm when compared with calcium-channel antagonists [21]. Cardioversion 
of AF is generally not recommended for asymptomatic or minimally symptomatic arrhythmias until the underlying problem is corrected. Indeed, correcting the underlying problem alone frequently leads to a spontaneous return to normal sinus rhythm (Class I, LOE A) [37]. In patients with stable hemodynamics, heart rate maintenance therapy is recommended. $\beta$-blockers, calcium-channel antagonists, and amiodarone are used to control heart rate. The target heart rate is $60-80 / \mathrm{min}$ at rest and $90-115 / \mathrm{min}$ during exercise. During the perioperative period, it is advisable to control heart rate at $90-115 / \mathrm{min}$, similar to the range recommended for rate control during exercise [37].

PAF results in loss of the "atrial kick" and a 20-30\% reduction in cardiac output. In patients with unstable hemodynamics (often seen after cardiovascular surgery), sinus rhythm is advantageous, and maintaining or restoring sinus rhythm is recommended [37]. It is recommend to restore sinus rhythm by pharmacologic cardioversion with ibutilide or via direct current cardioversion in patients who develop postoperative AF (Class IIa, LOE B) [37]. In the highly symptomatic patient or when rate control is difficult to achieve, cardioversion may be performed using the same precautions regarding anticoagulation as in nonsurgical cases. A variety of pharmacologic agents, including amiodarone, procainamide, ibutilide, and sotalol, may be effective to convert AF to sinus rhythm. Although a Class III agent was more effective than placebo for postoperative AF treatment in one study, orally administered sotalol is appealing in this situation because its $\beta$-blocking action slows the ventricular rate and its proarrhythmic toxicity is relatively low. However, this agent seems less effective than others for AF conversion. Otherwise, flecainide, dofetilide, ibutilide, propafenone (Class I, LOE A), and amiodarone (Class IIa, LOE A) are recommended for pharmacologic cardioversion. If these drugs are not effective, direct-current cardioversion can be performed. Antiarrhythmic medications should also be administered in an attempt to maintain sinus rhythm in patients with recurrent or refractory PAF. Dofetilide (Class I, LOE A) and amiodarone and ibutilide (Class IIa, LOE A) are recommended for maintaining sinus rhythm [37].

PAF is associated with an increased risk of cardiovascular and cerebrovascular events, especially strokes [3, 66]. Antithrombotic therapy is used in addition to heart-rate maintenance therapy in cases of PAF $>48$-h duration or in cases with a history of cerebrovascular thromboembolism. In contrast, anticoagulation in the perioperative period might increase the risk of bleeding or cardiac tamponade [67]. Antithrombotic agent selection should be based upon the absolute risks of stroke and bleeding and the relative risk and benefit for a given patient. Anticoagulation is more effective than aspirin to prevent stroke in patients with AF, as suggested by indirect comparisons and by a $33 \%$ risk reduction
(95\% CI 0.13-0.49) in a meta-analysis. Randomized trials involving high-risk AF patients (stroke rates $>6 \%$ per year) show larger relative risk reductions in response to adjusteddose orally administered anticoagulation therapy relative to aspirin, whereas the relative risk reductions are consistently smaller in trials of AF patients with lower stroke rates [68]. Thus, the first choice for antithrombotic therapy is anticoagulation. In those with contraindications to orally administered anticoagulation therapy, aspirin $81-325 \mathrm{mg}$ daily is recommended as an alternative to vitamin $\mathrm{K}$ antagonists [37]. One meta-analysis reported that adjusted-dose orally administered anticoagulation threapy is highly efficacious for stroke prevention, with a risk reduction of $62 \%$ (95\% CI $0.48-0.72$ ) versus placebo in an intention to treat analysis [68]. Protection against stroke due to AF is achieved at a prothrombin-time international normalized ratio (PT-INR) range of 2.0-3.0 [69]. For patients without mechanical heart valves who are at high risk of stroke, chronic anticoagulant therapy orally with a vitamin $\mathrm{K}$ antagonist is recommended in a dose-adjusted manner to achieve the target intensity PT-INR of 2.0-3.0, unless contraindicated [69]. Factors associated with highest risk for stroke in patients with AF are prior thromboembolism (e.g., stroke, transient ischemic attacks, or systemic embolism) and rheumatic mitral stenosis (Class I, LOE A) [37]. Although the optimal duration of antithrombotic therapy has not been established, in general, if normal sinus rhythm returns, anticoagulation therapy can be stopped because its risks outweigh the benefits [61]. The risk of bleeding is higher in elderly patients receiving antithrombotic therapy. PT-INR should be controlled to 1.6-2.6 in patients $\geq 75$ years of age [37]. In the clinical setting, anticoagulation therapy must be started when the risk-benefit ratio is favorable, especially in high-risk patients (e.g., elderly patients or those with uncontrolled hypertension or a history of bleeding). In the recent Randomized Evaluation of Long-Term Anticoagulation Therapy (RE-LY) trial, dabigatran administered at a dose of $150 \mathrm{mg}$ was associated with lower rates of stroke and systemic embolism (relative risk 0.66 ; 95\% CI $0.53-0.82$; $p<0.001$ ), but a similar rate of major hemorrhage (relative risk $0.93 ; 95 \%$ CI $0.81-1.07 ; p=0.31$ ) when compared with warfarin [70]. Although dabigatran is not a vitamin $\mathrm{K}$ antagonist, it is a potent, direct, competitive inhibitor of thrombin [70]. Another advantage of dabigatran is its lack of interactions with food and drugs. In addition, dabigatran does not require regular monitoring, and it has a quick onset of action and a short serum half-life [71]. In the future, use of dabigatran for perioperative management of PAF is expected to increase.

The impact of PAF on patient outcomes has prompted intense investigation into the optimal methods for prevention and treatment of this complication. PAF prevention 
is an important goal and requires specific perioperative management as well as other approaches. PAF is also associated with obesity, diabetes mellitus, and metabolic syndrome, which emphasizes the ongoing need for appropriate lifestyle management in individual patients.

Open Access This article is distributed under the terms of the Creative Commons Attribution License which permits any use, distribution, and reproduction in any medium, provided the original author(s) and the source are credited.

\section{References}

1. Jin R, Hiratzka LF, Grunkemeier GL, Krause A, Page US 3rd. Aborted off-pump coronary artery bypass patients have much worse outcomes than on-pump or successful off-pump patients. Circulation. 2005;112:I332-7.

2. Benjamin EJ, Wolf PA, D'Agostino RB, Silbershatz H, Kannel WB, Levy D. Impact of atrial fibrillation on the risk of death: the Framingham Heart Study. Circulation. 1998;98:946-52.

3. Villareal RP, Hariharan R, Liu BC, Kar B, Lee VV, Elayda M, Lopez JA, Rasekh A, Wilson JM, Massumi A. Postoperative atrial fibrillation and mortality after coronary artery bypass surgery. J Am Coll Cardiol. 2004;43:742-8.

4. Almassi GH, Schowalter T, Nicolosi AC, Aggarwal A, Moritz TE, Henderson WG, Tarazi R, Shroyer AL, Sethi GK, Grover FL, Hammermeister KE. Atrial fibrillation after cardiac surgery: a major morbid event? Ann Surg. 1997;226:501-11.

5. De Decker K, Jorens PG, Van Schil P. Cardiac complications after noncardiac thoracic surgery: an evidence-based current review. Ann Thorac Surg. 2003;75:1340-8.

6. Aranki SF, Shaw DP, Adams DH, Rizzo RJ, Couper GS, VanderVliet M, Collins JJ Jr, Cohn LH, Burstin HR. Predictors of atrial fibrillation after coronary artery surgery. Current trends and impact on hospital resources. Circulation. 1996;94:390-7.

7. Mathew JP, Parks R, Savino JS, Friedman AS, Koch C, Mangano DT, Browner WS. MultiCenter Study of Perioperative Ischemia Research Group Atrial fibrillation following coronary artery bypass graft surgery: predictors, outcomes, and resource utilization. JAMA. 1996;276:300-6.

8. Mathew JP, Fontes ML, Tudor IC, Ramsay J, Duke P, Mazer CD, Barash PG, Hsu PH, Investigators of the Ischemia Research and Education Foundation, Multicenter Study of Perioperative Ischemia Research Group. A multicenter risk index for atrial fibrillation after cardiac surgery. JAMA. 2004;291:1720-9.

9. Wang TJ, Parise H, Levy D, D’Agostino RB Sr, Wolf PA, Vasan RS, Benjamin EJ. Obesity and the risk of new-onset atrial fibrillation. JAMA. 2004;292:2471-7.

10. Echahidi N, Pibarot P, O'Hara G, Mathieu P. Mechanisms, prevention, and treatment of atrial fibrillation after cardiac surgery. J Am Coll Cardiol. 2008;51:793-801.

11. Echahidi N, Mohty D, Pibarot P, Després JP, O'Hara G, Champagne J, Philippon F, Daleau P, Voisine P, Mathieu P. Obesity and metabolic syndrome are independent risk factors for atrial fibrillation after coronary artery bypass graft surgery. Circulation. 2007;116:I213-9.

12. Kaw R, Hernandez AV, Masood I, Gillinov AM, Saliba W, Blackstone EH. Short- and long-term mortality associated with new-onset atrial fibrillation after coronary artery bypass grafting: a systematic review and meta-analysis. J Thorac Cardiovasc Surg. 2011;141:1305-12.

13. Ishii Y, Schuessler RB, Gaynor SL, Yamada K, Fu AS, Boineau JP, Damiano RJ Jr. Inflammation of atrium after cardiac surgery is associated with inhomogeneity of atrial conduction and atrial fibrillation. Circulation. 2005;111:2881-8.

14. Tselentakis EV, Woodford E, Chandy J, Gaudette GR, Saltman AE. Inflammation effects on the electrical properties of atrial tissue and inducibility of post-operative atrial fibrillation. J Surg Res. 2006;135:68-75.

15. Wijeysundera DN, Beattie WS, Rao V, Karski J. Calcium antagonists reduce cardiovascular complications after cardiac surgery: a meta-analysis. J Am Coll Cardiol. 2003;41:1496-505.

16. Murakawa T, Kubota T, Matsuki A. Therapeutic drug monitoring in perioperative period-management of atrial fibrillation in a patient with bradycardia due to relative overdose of digitalis. Masui. 1997;46:521-4.

17. Andrews TC, Reimold SC, Berlin JA, Antman EM. Prevention of supraventricular arrhythmias after coronary artery bypass surgery. A meta-analysis of randomized control trials. Circulation. 1991;84:III236-44.

18. Zeltser D, Justo D, Halkin A, Rosso R, Ish-Shalom M, Hochenberg M, Viskin S. Drug-induced atrioventricular block: prognosis after discontinuation of the culprit drug. J Am Coll Cardiol. 2004:44:105-8.

19. Podrid PJ. Prevention of post-operative atrial fibrillation: what is the best approach? J Am Coll Cardiol. 1999;34:340-2.

20. Atarashi H, Kuruma A, Yashima M, Saitoh H, Ino T, Endoh Y, Hayakawa H. Pharmacokinetics of landiolol hydrochloride, a new ultra-short-acting $\beta$-blocker, in patients with cardiac arrhythmias. Clin Pharmacol Ther. 2000;68:143-50.

21. Balser JR, Martinez EA, Winters BD, Perdue PW, Clarke AW, Huang W, Tomaselli GF, Dorman T, Campbell K, Lipsett P, Breslow MJ, Rosenfeld BA. Beta-adrenergic blockade accelerates conversion of postoperative supraventricular tachyarrhythmias. Anesthesiology. 1998;89:1052-9.

22. van Dantzig JM, Koster RW, Biervliet JD. Treatment with esmolol of ventricular fibrillation unresponsive to lidocaine and procainamide. J Cardiothorac Vasc Anesth. 1991;5:600-3.

23. Ferguson TB Jr, Coombs LP, Peterson ED, Society of Thoracic Surgeons National Adult Cardiac Surgery Database. Preoperative $\beta$-blocker use and mortality and morbidity following CABG surgery in North America. JAMA. 2002;287:2221-7.

24. Stone JG, Foëx P, Sear JW, Johnson LL, Khambatta HJ, Triner L. Myocardial ischemia in untreated hypertensive patients: effect of a single small oral dose of a $\beta$-adrenergic blocking agent. Anesthesiology. 1988;68:495-500.

25. Mangano DT, Layug EL, Wallace A, Tateo I. Effect of atenolol on mortality and cardiovascular morbidity after noncardiac surgery. Multicenter Study of Perioperative Ischemia Research Group. N Engl J Med. 1996;335:1713-20.

26. Wallace A, Layug B, Tateo I, Li J, Hollenberg M, Browner W, Miller D, Mangano DT. Prophylactic atenolol reduces postoperative myocardial ischemia. McSPI Research Group. Anesthesiology. 1998;88:7-17.

27. Raby KE, Brull SJ, Timimi F, Akhtar S, Rosenbaum S, Naimi C, Whittemore AD. The effect of heart rate control on myocardial ischemia among high-risk patients after vascular surgery. Anesth Analg. 1999;88:477-82.

28. Auerbach $\mathrm{AD}$, Goldman L. $\beta$-Blockers and reduction of cardiac events in noncardiac surgery: scientific review. JAMA. 2002;287: $1435-44$.

29. Burgess DC, Kilborn MJ, Keech AC. Interventions for prevention of post-operative atrial fibrillation and its complications after cardiac surgery: a meta-analysis. Eur Heart J. 2006;27:2846-57.

30. Poldermans D, Boersma E, Bax JJ, Thomson IR, van de Ven LL, Blankensteijn JD, Baars HF, Yo TI, Trocino G, Vigna C, Roelandt JR, van Urk $H$. The effect of bisoprolol on perioperative mortality and myocardial infarction in high-risk patients undergoing vascular surgery. Dutch Echocardiographic Cardiac Risk 
Evaluation Applying Stress Echocardiography Study Group. N Engl J Med. 1999;341:1789-94.

31. Poldermans D, Boersma E, Bax JJ, Thomson IR, Paelinck B, van de Ven LL, Scheffer MG, Trocino G, Vigna C, Baars HF, van Urk H, Dutch Echocardiographic Cardiac Risk Evaluation Applying Stress Echocardiography Study Group. Bisoprolol reduces cardiac death and myocardial infarction in high-risk patients as long as 2 years after successful major vascular surgery. Eur Heart J. 2001;22:1353-8.

32. Coleman CI, Perkerson KA, Gillespie EL, Kluger J, Gallagher R, Horowitz $\mathrm{S}$, White CM. Impact of prophylactic postoperative $\beta$ blockade on post-cardiothoracic surgery length of stay and atrial fibrillation. Ann Pharmacother. 2004;38:2012-6.

33. Crystal E, Garfinkle MS, Connolly SS, Ginger TT, Sleik K, Yusuf SS. Interventions for preventing post-operative atrial fibrillation in patients undergoing heart surgery. Cochrane Database Syst Rev. 2004;4:CD003611.

34. Lindenauer PK, Pekow P, Wang K, Mamidi DK, Gutierrez B, Benjamin EM. Perioperative $\beta$-blocker therapy and mortality after major noncardiac surgery. N Engl J Med. 2005;353:349-61.

35. POISE Study Group, Devereaux PJ, Yang H, Yusuf S, Guyatt G, Leslie K, Villar JC, Xavier D, Chrolavicius S, Greenspan L, Pogue J, Pais P, Liu L, Xu S, Málaga G, Avezum A, Chan M, Montori VM, Jacka M, Choi P. Effects of extended-release metoprolol succinate in patients undergoing non-cardiac surgery (POISE trial): a randomised controlled trial. Lancet. 2008;371:1839-47.

36. Bangalore S, Wetterslev J, Pranesh S, Sawhney S, Gluud C, Messerli FH. Perioperative beta blockers in patients having noncardiac surgery: a meta-analysis. Lancet. 2008;372:1962-76.

37. Fuster V, Rydén LE, Cannom DS, Crijns HJ, Curtis AB, Ellenbogen KA, Halperin JL, Kay GN, Le Huezey JY, Lowe JE, Olsson SB, Prystowsky EN, Tamargo JL, Wann LS, Smith SC Jr, Priori SG, Estes NA 3rd, Ezekowitz MD, Jackman WM, January CT, Lowe JE, Page RL, Slotwiner DJ, Stevenson WG, Tracy CM, Jacobs AK, Anderson JL, Albert N, Buller CE, Creager MA, Ettinger SM, Guyton RA, Halperin JL, Hochman JS, Kushner FG, Ohman EM, Stevenson WG, Tarkington LG, Yancy CW, American College of Cardiology Foundation/American Heart Association Task Force. ACCF/AHA/HRS focused updates incorporated into the ACC/AHA/ESC 2006 guidelines for the management of patients with atrial fibrillation: a report of the American College of Cardiology Foundation/American Heart Association Task Force on practice guidelines. Circulation. 2011;2011(123):e269-367.

38. Eagle KA, Guyton RA, Davidoff R, Edwards FH, Ewy GA, Gardner TJ, Hart JC, Herrmann HC, Hillis LD, Hutter AM Jr, Lytle BW, Marlow RA, Nugent WC, Orszulak TA, American College of Cardiology, American Heart Association. ACC/AHA, guideline update for coronary artery bypass graft surgery: a report of the American College of Cardiology/American Heart Association Task Force on Practice Guidelines (Committee to Update the 1999 Guidelines for Coronary Artery Bypass Graft Surgery). Circulation. 2004;2004(110): $340-437$.

39. Fleisher LA, Beckman JA, Brown KA, Calkins H, Chaikof EL, Fleischmann KE, Freeman WK, Froehlich JB, Kasper EK, Kersten JR, Riegel B, Robb JF. 2009 ACCF/AHA focused update on perioperative beta blockade incorporated into the ACC/AHA 2007 guidelines on perioperative cardiovascular evaluation and care for noncardiac surgery: a report of the American College of Cardiology Foundation/American Heart Association Task Force on Practice Guidelines. Circulation. 2009;120:e169-276.

40. Daoud EG, Strickberger SA, Man KC, Goyal R, Deeb GM, Bolling SF, Pagani FD, Bitar C, Meissner MD, Morady F. Preoperative amiodarone as prophylaxis against atrial fibrillation after heart surgery. N Engl J Med. 1997;337:1785-91.
41. Guarnieri T, Nolan S, Gottlieb SO, Dudek A, Lowry DR. Intravenous amiodarone for the prevention of atrial fibrillation after open heart surgery: the Amiodarone Reduction in Coronary Heart (ARCH) trial. J Am Coll Cardiol. 1999;34:343-7.

42. Mitchell LB, Exner DV, Wyse DG, Connolly CJ, Prystai GD, Bayes AJ, Kidd WT, Kieser T, Burgess JJ, Ferland A, MacAdams CL, Maitland A. Prophylactic oral amiodarone for the prevention of arrhythmias that begin early after revascularization, valve replacement, or repair: PAPABEAR: a randomized controlled trial. JAMA. 2005;294:3093-100.

43. Patel AA, White CM, Gillespie EL, Kluger J, Coleman CI. Safety of amiodarone in the prevention of post-operative atrial fibrillation: a meta-analysis. Am J Health Syst Pharm. 2006;63:829-37.

44. Marín F, Pascual DA, Roldán V, Arribas JM, Ahumada M, Tornel PL, Oliver C, Gómez-Plana J, Lip GY, Valdés M. Statins and postoperative risk of atrial fibrillation following coronary artery bypass grafting. Am J Cardiol. 2006;97:55-60.

45. Patti G, Chello M, Candura D, Pasceri V, D’Ambrosio A, Covino E, Di Sciascio G. Randomized trial of atorvastatin for reduction of postoperative atrial fibrillation in patients undergoing cardiac surgery: results of the ARMYDA-3 (Atorvastatin for Reduction of Myocardial Dysrhythmia After cardiac surgery) study. Circulation. 2006;114:1455-61.

46. Mariscalco G, Lorusso R, Klersy C, Ferrarese S, Tozzi M, Vanoli D, Domenico BV, Sala A. Observational study on the beneficial effect of preoperative statins in reducing atrial fibrillation after coronary surgery. Ann Thorac Surg. 2007;84:1158-64.

47. Winchester DE, Wen X, Xie L, Bavry AA. Evidence of preprocedural statin therapy a meta-analysis of randomized trials. J Am Coll Cardiol. 2010;56:1099-109.

48. Abdelhadi RH, Gurm HS, Van Wagoner DR, Chung MK. Relation of an exaggerated rise in white blood cells after coronary bypass or cardiac valve surgery to development of atrial fibrillation post-operatively. Am J Cardiol. 2004;93:1176-8.

49. Lamm G, Auer J, Weber T, Berent R, Ng C, Eber B. Postoperative white blood cell count predicts atrial fibrillation after cardiac surgery. J Cardiothorac Vasc Anesth. 2006;20:51-6.

50. Halonen J, Halonen P, Järvinen O, Taskinen P, Auvinen T, Tarkka M, Hippeläinen M, Juvonen T, Hartikainen J, Hakala T. Corticosteroids for the prevention of atrial fibrillation after cardiac surgery: a randomized controlled trial. JAMA. 2007;297:1562-7.

51. Cheruku KK, Ghani A, Ahmad F, Pappas P, Silverman PR, Zelinger A, Silver MA. Efficacy of nonsteroidal anti-inflammatory medications for prevention of atrial fibrillation following coronary artery bypass graft surgery. Prev Cardiol. 2004;7:13-8.

52. Satur CM. Magnesium and cardiac surgery. Ann R Coll Surg Engl. 1997;79:349-54.

53. Vyvyan HA, Mayne PN, Cutfield GR. Magnesium flux and cardiac surgery: a study of the relationship between magnesium exchange, serum magnesium levels and post-operative arrhythmias. Anaesthesia. 1994;49:245-9.

54. Miller S, Crystal E, Garfinkle M, Lau C, Lashevsky I, Connolly SJ. Effects of magnesium on atrial fibrillation after cardiac surgery: a meta-analysis. Heart. 2005;91:618-23.

55. Wijeysundera DN, Beattie WS, Djaiani G, Rao V, Borger MA, Karkouti K, Cusimano RJ. Off-pump coronary artery surgery for reducing mortality and morbidity: meta-analysis of randomized and observational studies. J Am Coll Cardiol. 2005;46:872-82.

56. Chu D, Bakaeen FG, Dao TK, Lemaire SA, Coselli JS, Huh J. On-pump versus off-pump coronary artery bypass grafting in a cohort of 63,000 patients. Ann Thorac Surg. 2009;87:1820-6.

57. Almassi GH, Pecsi SA, Collins JF, Shroyer AL, Zenati MA, Grover FL. Predictors and impact of postoperative atrial fibrillation on patients' outcomes: a report from the Randomized On Versus Off Bypass trial. J Thorac Cardiovasc Surg. 2011 [Epub ahead of print]. 
58. Moller CH, Perko MJ, Lund JT, Andersen LW, Kelbaek H, Madsen JK, Winkel P, Gluud C, Steinbrüchel DA. No major differences in 30-day outcomes in high-risk patients randomized to off-pump versus on-pump coronary bypass surgery: the best bypass surgery trial. Circulation. 2010;121(4):498-504.

59. Daoud EG, Snow R, Hummel JD, Kalbfleisch SJ, Weiss R, Augostini R. Temporary atrial epicardial pacing as prophylaxis against atrial fibrillation after heart surgery: a meta-analysis. J Cardiovasc Electrophysiol. 2003;14:127-32.

60. Fan K, Lee KL, Chiu CS, Lee JW, He GW, Cheung D, Sun MP, Lau CP. Effects of biatrial pacing in prevention of post-operative atrial fibrillation after coronary artery bypass surgery. Circulation. 2000;102:755-60.

61. Epstein AE, Alexander JC, Gutterman DD, Maisel W, American College of Chest Physicians. Anticoagulation: American College of Chest Physicians guidelines for the prevention and management of postoperative atrial fibrillation after cardiac surgery. Chest. 2005;128(2 Suppl):24-7.

62. Wyse DG, Waldo AL, DiMarco JP, Domanski MJ, Rosenberg Y, Schron EB, Kellen JC, Greene HL, Mickel MC, Dalquist JE, Atrial Fibrillation Follow-up Investigation of Rhythm Management (AFFIRM) Investigators. A comparison of rate control and rhythm control in patients with atrial fibrillation. N Engl J Med. 2002;347:1825-33.

63. Hagens VE, Ranchor AV, Van Sonderen E, Bosker HA, Kamp O, Tijssen JG, Kingma JH, Crijns HJ, RACE Study Group. Effect of rate or rhythm control on quality of life in persistent atrial fibrillation. Results from the Rate Control Versus Electrical Cardioversion (RACE) Study. J Am Coll Cardiol. 2004;43:241-7.

64. Beattie WS, Wijeysundera DN, Karkouti K, McCluskey S, Tait G. Does tight heart rate control improve beta-blocker efficacy?
An updated analysis of the noncardiac surgical randomized trials. Anesth Analg. 2008;106:1039-48.

65. Farshi R, Kistner D, Sarma JS, Longmate JA, Singh BN. Ventricular rate control in chronic atrial fibrillation during daily activity and programmed exercise: a crossover open-label study of five drug regimens. J Am Coll Cardiol. 1999;33:304-10.

66. Bucerius J, Gummert JF, Borger MA, Walther T, Doll N, Onnasch JF, Metz S, Falk V, Mohr FW. Stroke after cardiac surgery: a risk factor analysis of 16,184 consecutive adult patients. Ann Thorac Surg. 2003;75:472-8.

67. Meurin P, Weber H, Renaud N, Larrazet F, Tabet JY, Demolis P, Ben Driss A. Evolution of the postoperative pericardial effusion after day 15: the problem of the late tamponade. Chest. 2004;125:2182-7.

68. Hart RG, Benavente O, McBride R, Pearce LA. Antithrombotic therapy to prevent stroke in patients with atrial fibrillation: a meta-analysis. Ann Intern Med. 1999;131:492-501.

69. Hylek EM, Go AS, Chang Y, Jensvold NG, Henault LE, Selby JV, Singer DE. Effect of intensity of oral anticoagulation on stroke severity and mortality in atrial fibrillation. N Engl J Med. 2003;349:1019-26.

70. Connolly SJ, Ezekowitz MD, Yusuf S, Eikelboom J, Oldgren J, Parekh A, Pogue J, Reilly PA, Themeles E, Varrone J, Wang S, Alings M, Xavier D, Zhu J, Diaz R, Lewis BS, Darius H, Diener HC, Joyner CD, RE-LY Steering Committee and Investigators. Dabigatran versus warfarin in patients with atrial fibrillation. N Engl J Med. 2009;361:1139-51.

71. Stangier J. Clinical pharmacokinetics and pharmacodynamics of the oral direct thrombin inhibitor dabigatran etexilate. Clin Pharmacokinet. 2008;47:285-95. 